\title{
Predictors of Mothers' Behavior in Diarrhea Prevention
}

\author{
Helmi Rumbo 1,*, Susheewa Wichaikull2, and Boosaba Sanguanprasit ${ }^{2}$ \\ ${ }^{1}$ Ners Profession Study Program, STIK Indonesia Jaya, Palu, Indonesia \\ ${ }^{2}$ Boromarajonani College of Nursing Nopparat Vajira, Bangkok, 10230, Thailand \\ ORCID \\ Helmi Rumbo: https://orcid.org/0000-0003-2000-3244
}

Corresponding Author: Helmi

Rumbo; email:

helmi.rumbo@ymail.com

Published: 7 February 2022

Publishing services provided by

Knowledge E

(c) Helmi Rumbo et al. This

article is distributed under the

terms of the

Attribution License, which

permits unrestricted use and

redistribution provided that the

original author and source are

credited.

Selection and Peer-review under the responsibility of the IVCN

Conference Committee.
Abstract. Diarrhea causes severe dehydration and depleted nutrients due to the decreased nutritional intake, resulting in malnutrition in children. Diarrhea can also lead to death from dehydration if untreated. Globally, about 1.7 billion cases of childhood diarrhea occurred in 2017. In Indonesia, deaths caused by diarrhea in 2020 accounted for $4.55 \%$ of the 250,600 deaths of children under five years old and $9.8 \%$ of the 20,266 deaths of newborns. This study aimed to determine the predictors of mothers' behavior in preventing diarrhea in children under five years old. The sample included mothers with children aged 1 - 5 years, who were recruited using purposive sampling. Roughly 300 mothers were interviewed using a questionnaire. Binary regression was used to measure associations between predictors and mothers' behaviors. The results showed that the factors that significantly predicted mothers' behaviors included perceived susceptibility to diarrhea $(p<0.01)$, perceived severity of diarrhea $(p<0.01)$, perceived barriers to diarrhea prevention behaviors $(p<0.01)$ and perceived self-efficacy in diarrhea prevention behaviors $(p<0.01)$. The model developed could predict $39.2 \%$ of the variation in mothers' behaviors in preventing diarrhea in children. The strongest predictor of mothers' behaviors was perceived selfefficacy in diarrhea prevention behaviors. The odds of carrying out good prevention behaviors were ten times greater for mothers who had a high level of perceived self-efficacy in preventing diarrhea in children. These results indicated that those who believe in their ability to succeed in performing an action can perform healthy behaviors.

Keywords: perceived, mothers, behavior, diarrhea

\section{Introduction}

Concurring to an unused report by UNICEF and WHO that stated billions of individuals around the world are proceeding to endure from destitute get to water, sanitation and cleanliness. The information (2017) appearing about three billion individuals need essential handwashing facilities at home, such as water and soap/cleanser. It moreover appears that about three quarters of the populations of the least developed countries 
Each year, about 297,000 children five years old die due to diarrhea, associated with lacking Water - Sanitation - Hygiene (WASH). Living in the destitute sanitation and using sullied water could be an access to transmission of diseases such as cholera, diarrhea, hepatitis A, and typhoid [1]. Globally, in 2017 there were about 1.7 billion cases of childhood diarrhea and it kills about 525,000 children every year [2][3]. According to data from Ministry of Health Indonesia in 2020, the number of deaths caused by diarrhea accounted for $4,55 \%$ of the 250,600 death of children five years old; $9,8 \%$ of the 20,266 deaths of infant.

Diarrhea in children is the second driving cause of passing those children aged five years old. According to data about 370,000 children die caused by diarrhea in 2019 . The foremost extreme danger postured by diarrhea is dehydration. Amid a scene of loose bowels, water and electrolytes counting sodium, chloride, potassium and bicarbonate are misplaced through fluid stools, vomit, sweat, pee and breathing. Children with loose bowels gets to be got dried out when these conditions are not treated. In addition, loose bowels may be a major cause of malnutrition, making the children more vulnerable to future bouts of loose bowels and to other disease or complication [2][3]. A critical extend of diarrheal disease can be anticipated through secure drinking-water and satisfactory sanitation and hygiene [5][6].

One role of a mother in family is to exemplify leadership in health. Mother encompasses a central role as decision creator, teacher, counselor and caregiver within the house. Amid the prime period of development and advancement in children, the mothers' part in illness avoidance is vital to avoid hazard to children's wellbeing [7][8][9]. In order to prevent diarrhea in children, mother should be adhering to good personal hygiene like washing their hands with soap and clean water. This incorporates after defecation, after taking care of their children's feces disposal, sometime recently planning food in their family and sometime recently feeding their children or breastfeeding their babies, monitor intravenous liquids, changing a diaper immediately in case it is messy to dodge irritation and avoid the spread of disease by washing hands some time recently and after a treatment. Clean and healthy living behavior certainly will maintain a strategic distance from diarrhea in children [10][111.

Factors that influence mothers' behaviors include intra-personal factors, inter-personal factors and social-environment factors. Intra-personal factors consist of personal characteristics like knowledge, level of education, beliefs, motivation, personality traits, age and perceptions. When mothers have a good understanding of the potential causes of diarrhea and start believing the serious threat of diarrhea, this might motivate these mothers to perform health behaviors. In addition to knowledge 
about diarrhea, any previous experience of diarrhea would help mothers to decide on the best course of avoiding it [12][13][14].

Based on several studies, it has been found that there was a linear correlation between age and caregivers' behaviors to avoiding loose bowels in children [15][32]. However, other studies found that there was no significant association between age and diarrhea prevention behaviors [16][17]. It has been proofed that there was a significant association between education and diarrhea prevention [16][37]. In contrast, another study found that there was no significant association between education and diarrhea prevention behaviors [17]. It has been found that there was a significant relationship between family's income and caregiver's diarrhea prevention behaviors [17][32]. However, another study found that there was no significant association between family's income and caregiver's diarrhea prevention behaviors [16]

Kundu found that there was a significant positive correlation between perceived vulnerability to diarrhea, perceived seriousness of diarrhea, perceived benefits of diarrhea avoidance behaviors and mothers' prevention behavior in children [18]. In contrast, a study by Morgan shows no significant correlation between perceived susceptibility to diarrhea, perceived severity of diarrhea, perceived benefits of practices and diarrhea prevention behaviors. It has been found that there was a negative correlation between perceived barriers to practices and diarrhea prevention behaviors [15], while another study found that there was no significant correlation between perceived barriers to diarrhea prevention behaviors and diarrhea prevention behaviors [18].

Central Sulawesi ranked at the fifth among places with the highest incidence of diarrhea in Indonesia with diarrhea incidence among children under-5 year was estimated at $6.8 \%$ [19]. Central Sulawesi covers 11 Districts including Buol. Based on a survey, only $24.2 \%$ of Buol people performed hygienic and healthy behaviors. Out of 27,987 family units, $47.2 \%$ families had appropriate dumps for their waste disposal, 31.8\% had great implies to handle their wastewater, $65.1 \%$ had secure drinking water and $45.5 \%$ had restroom [20]. This circumstance had put the children at high hazard of having diarrhea since of poor environmental sanitation and destitute individual hygiene. In protect children from diarrhea, mothers' behaviors are very important. Early diagnosis or treatment always gives opportunities for the better results [21]. Therefore, a research study is needed to determine factors that predict mothers' behaviors in preventing diarrhea in children under five. 


\section{Methods and Equipment}

\subsection{Method}

This research study was a cross-sectional survey design to determine factors predicting mothers' behaviors in preventing diarrhea in children aged 1 - 5 in Buol District, Central Sulawesi, Indonesia.

\subsection{Population and Sample}

The population of this study was mothers who had children under five, living in Buol District. The total children population was 13,975 [19]. The sample size for this study was 300 mothers. This study used multistage sampling technique. Most area of Buol is located along the coastline [19]. The population was stratified into two groups based on location of residence: lowlands and highlands to represent all population in Buol District. Each area consisted of 10 sub-districts, including 75 villages in lowlands (9,943 children) and 7 sub-districts including 40 villages in highlands (4,032 children).

The number of samples of each village was estimated using proportional to size. Systematic random sampling technique would use to select the house which based on a list all of households' number that registered or listed on the Community Leader. However, only two villages provided a list of children's names, and the data did not include the home address. The researcher decided to change method into purposive sampling method based upon inclusion criteria. Finally, a sample of 300 mothers included 210 from lowlands and 90 from highlands. If the mother had more than one child aged 1 - 5 years old, this study involves of younger child. The number of participating mothers for each village was 31, 85, 31, 63, 53, and 37 (Bukaan, Kel. Buol, Bunobogu, Paleleh, Air Terang, and Mooyong respectively).

The setting and population were determined based upon inclusion and exclusion criteria of this study.

Inclusion Criteria: Mother who was able to write, read and speaks Bahasa Indonesia; Mother with children aged 1 - 5 years; Mothers who provide care to their children aged 1 - 5 years. On the other hand, the exclusion Criteria: Mothers who was not able to perform daily activity by themselves included physical disabilities and mental disorders. 


\subsection{Equipment}

The survey of mothers' behaviors in diarrhea prevention comprised of four parts counting common characteristics, information of loose bowels, perceptions toward loose bowels in children, and mothers' behaviors in loose bowels avoidance. Common characteristics comprise of socioeconomics information of the mother-child dyad such as mothers' age, marital status, occupation, child's age, and episode of loose bowels within the final month.

The independent factors were composed of age, knowledge of diarrhea, and mothers' recognition toward diarrhea in children. Mothers were inquired about their knowledge in recognizing loose bowels in children, and this portion given three reactions (yes, no, and don't know). The score was given for each item (1 and separately). It was categorized into three bunches: destitute (0\%-59\%), moderate (60\%-79\%), and great (80\%-100\%). In this consider, the KR-20 was .708.

Perceived vulnerability to diarrhea and perceived seriousness of diarrhea given five reactions. The score was given for each thing agreeing to the reply such as exceedingly likely, likely, not beyond any doubt, impossible, and profoundly improbable (4, 3, 2, 1, and separately). The full score had been categorized into three bunches: low, moderate, and high. The Cronbach's Alpha of perceived vulnerability to diarrhea was .951; perceived seriousness of the runs was .856 .

Perceived benefits of diarrhea anticipation behaviors given five reactions, and the score was given for each thing concurring to the reply such as emphatically concur, agree, questionable, oppose this idea, and unequivocally disagree $(4,3,2,1$, and separately). The overall score had been categorized into three bunches: low, moderate, and high. The Cronbach's Alpha was .897.

Perceived obstructions to diarrhea prevention behaviors given three reactions (yes, no, and why). The score was given for each item concurring to the reply ( 0 and 1 individually). The entire score had been categorized into three bunches: low, moderate, and high. The Cronbach's Alpha was .808.

Mothers were evaluated for their behaviors in every day schedules for avoiding diarrhea in children, which included giving secure drinking water, arranging the feces legitimately, washing hands, and secure nourishment arrangement. This portion given three reactions (continuously, not continuously, and never). The score was given for each item concurring to the option ( 3,2 , and 1 separately). The whole score had been categorized into three bunches (moo, direct, and tall). The Cronbach's Alpha was .863. 


\subsection{Data Collection}

Data were collected by using a structured questionnaire. Each mother was interviewed directly by the researcher at their house. The researcher met 300 mothers who had met the inclusion criteria. Researcher started a conversation with an introduction and explanation of this study. The researcher also explained that the data was used only for research study purpose. Confidentiality was provided during data collecting and analyzing process. The researcher provides the informed consent to be signed by those mothers who understood about the instrument sheet and had agreed to involve in this study voluntarily. The mothers had rights to refuse answering any questions, which made the mothers felt uncomfortable. If there were any questions or the mothers would like to obtain more information, they can ask the researcher directly and any time.

Before the researcher left the house, the questionnaire had been re-checked for the completeness. Overall, the data collection process spent time for about 20 - 30 minutes. Researcher had guaranteed that procedure(s) was exactly the same as indicated in the result of research study. At the end of the session, the researcher acknowledged the participant for their time and willingness.

\subsection{Data Analysis}

The data had been coded and analyzed by using Statistical Package for Social Science (SPSS). Descriptive analyses, bivariate analyses and multivariate analyses were performed. Since the normality tests for the dependent variable was not normal distribution. Therefore, the data $(n=300)$ analyzed by using nonparametric statistics and logistic regression.

Binary logistic regression was used to determine predictors of mothers' behaviors in diarrhea prevention. Logistic regression is used to predict categorical dependent variable. Logistic regression transforms the probability of an even occurring into the odds. Odds means the ratio of two probabilities, which is the probability of an event occurring and the probability that it will not occur. Binary logistic regression required the independent variable to be category (nominal and ordinal scaled) and the dependent variable as a dichotomous [22]. 
TABLE 1: Number and percentage of general characteristics of mothers $(n=300)$

\begin{tabular}{l|l|l} 
Variables & Frequency & Percentage \\
\hline $\begin{array}{l}\text { Age } \\
<20 \text { years }\end{array}$ & 11 & 3.6 \\
\hline $\begin{array}{l}20-35 \text { years } \geq 36 \text { years Mean } \pm \text { S.D } \\
29.9 \pm 7.3 \text { years }\end{array}$ & 22168 & 73.722 .7 \\
\hline $\begin{array}{l}\text { Min - Max = 18 - } 48 \text { years } \\
\text { Level of education }\end{array}$ & 103 & 34.3 \\
\hline $\begin{array}{l}\text { Lower than Junior High School } \\
\text { Junior High School and above }\end{array}$ & 197 & 65.7 \\
\hline $\begin{array}{l}\text { Occupation } \\
\text { Housewife }\end{array}$ & 251 & 83.7 \\
\hline Employees Farmer Entrepreneur & 29911 & 9.73 .03 .7 \\
\hline Family's income & 118 & 39.3 \\
\hline Not sufficient & 182 & 60.7
\end{tabular}

\subsection{Ethical Consideration}

This consider was affirmed by The Ethical Review Board of Boromarajonani College of Nursing Nopparat Vajira, ERB No. 22/2558.

\section{Results}

\subsection{Demographic Data and Mothers' Behaviors in Preventing Diar- rhea in Children Aged 1 -- 5 Years}

The general characteristics of the mothers included age, level of education, occupation, sufficiency of family's income and household members. The results are displayed in Table 2. Data revealed that mothers' age ranged from 18 to 48 years, with the mean of age 29.9 years $(S D=7.3$ ). Almost three-fourths of mothers aged 20 to 35 years and $97.3 \%$ of the mothers were married. About $65.7 \%$ of mothers completed Junior High School or the nine-year compulsory education, $83.7 \%$ of mothers were unemployed or being a housewife and $60.7 \%$ had sufficient with family's income per month. Majority of the mothers lived in households that had more than five people. 
TABLE 2: The relationship between knowledge, perception, social support of mothers and mother's behaviors in preventing diarrhea in children

\begin{tabular}{|c|c|c|c|c|c|c|}
\hline \multirow[t]{2}{*}{ Variables } & \multicolumn{2}{|c|}{ Mother's Behaviors } & \multirow[t]{2}{*}{ Tot. } & \multirow[t]{2}{*}{$\chi^{2}$} & \multirow[t]{2}{*}{$\mathrm{p}$} & \multirow[t]{2}{*}{ phi } \\
\hline & $\begin{array}{l}\text { Needs } \\
\text { improved }\end{array}$ & Good & & & & \\
\hline Knowledge of diarrhea & & & & 0.0 & 0.789 & -0.0 \\
\hline Needs improvement & 36 (30.8 \%) & 81 (69.2 \%) & 117 & & & \\
\hline Good & 59 (32.2 \%) & 124 (67.8 \%) & 183 & & & \\
\hline $\begin{array}{l}\text { Perceived susceptibility } \\
\text { to diarrhea }\end{array}$ & & & & 25.0 & 0.000 & 0.3 \\
\hline Low-Fair & 81 (41.5 \%) & 144 (58.5 \%) & 195 & & & \\
\hline High & 14 (13.3 \%) & 91 (86.7%) & 105 & & & \\
\hline $\begin{array}{l}\text { Perceived severity of } \\
\text { diarrhea }\end{array}$ & & & & 7.2 & 0.007 & -0.1 \\
\hline Low-Fair & 36 (24.3 \%) & 112 (75.7 \%) & 148 & & & \\
\hline High & 59 (38.8 \%) & 93 (61.2 \%) & 152 & & & \\
\hline $\begin{array}{l}\text { Perceived benefits of } \\
\text { DPH }\end{array}$ & & & & 26.2 & 0.000 & 0.3 \\
\hline Low-Fair & 82 (41.6 \%) & 115 (58.4 \%) & 197 & & & \\
\hline High & 13 (12.6 \%) & 90 (87.4 \%) & 103 & & & \\
\hline $\begin{array}{l}\text { Perceived barriers to } \\
\text { DPH }\end{array}$ & & & & 36.5 & 0.000 & -0.3 \\
\hline No barrier & $2(2.8 \%)$ & 70 (97.2 \%) & 72 & & & \\
\hline 1 and more barriers & 93 (40.8 \%) & 135 (59.2 \%) & 228 & & & \\
\hline $\begin{array}{l}\text { Perceived self-efficacy } \\
\text { in DPH }\end{array}$ & & & & 47.6 & 0.000 & 0.4 \\
\hline Low-Fair & 92 (43.8\%) & 118 (56.2 \%) & 210 & & & \\
\hline High & $3(3.3 \%)$ & 87 (96.7%) & 90 & & & \\
\hline $\begin{array}{l}\text { Social support in rela- } \\
\text { tion to prevent diarrhea }\end{array}$ & & & & 15.1 & 0.000 & 0.2 \\
\hline Less & 93 (35.8 \%) & 167 (64.2 \%) & 260 & & & \\
\hline More & 2 (31.7 \%) & 38 (68.3 \%) & 40 & & & \\
\hline
\end{tabular}

\subsection{Knowledge of Diarrhea, Perception toward Diarrhea, Social Support and Mothers' Behaviors in Preventing Diarrhea in Children Aged 1 -- 5 Years}

In this section, all variables were re-classified into two categories by using to $80.0 \%$ cut off point of the total score. Those mothers with a score greater than $79 \%$ were categorized either good or high. However, perceived barrier of diarrhea was classified into two categories, including no barrier and one/more barriers. 


\subsection{Factors Predicting Mothers' Behaviors in Preventing Diarrhea in Children Aged 1 -- 5 Years}

Binary logistic regression was used to assess the effect of independent variables on mothers' behavior in preventing diarrhea in children aged 1 - 5 years.

\subsubsection{Backward Stepwise Method}

By using backward logistic regression analysis, the method yielded the full model and the best model (the parsimonious model) to predict mothers' behavior in preventing diarrhea in children. The full model consisted of mothers' age, level of education, sufficiency of family's income, level of knowledge, perceived susceptibility to diarrhea, perceived severity of diarrhea, perceived benefits of diarrhea prevention behaviors, perceived barriers to diarrhea prevention behaviors, perceived self-efficacy in diarrhea prevention behaviors and social support in relation to prevent diarrhea in children. The Nagelkerke R2 was 0.426 ; it means $42.6 \%$ of mothers' behavior in preventing diarrhea in children was explained by this model (see Table 3). Backward stepwise method was used to assess the effect of each specified independent variable and forward stepwise method was used to identify the best predicting model which was determined by using Hosmer and Lemeshow statistics.

The results of the full model of logistic regression which all specified independent variables were included. $B$ values are the logistic coefficient that can be used to create a predictive equation, which is expressed in term of probability of having good preventive behavior. Exp. (B) or Odds Ratio (ORs) presents the effect of corresponding independent variable on odds of having good behaviors. Out of ten variables, five were found to be significantly predicting mothers' behaviors. These factors included income (OR $=1.963$, $p<0.05$ ), perceived susceptibility to diarrhea ( $O R=2.577, p<0.05)$, perceived severity of diarrhea $(O R=0.294, p<0.01$ ), perceived barriers to diarrhea prevention behaviors $(\mathrm{OR}=0.127, \mathrm{p}<0.01)$ and perceived self-efficacy in diarrhea prevention behaviors $(\mathrm{OR}=8.635, \mathrm{p}<0.01)$. Other factors did not contribute significantly to the predictive ability of the model included age, education, knowledge, perceived benefits of diarrhea prevention behaviors and social support. Backward stepwise method which are shown in table 3. 
TABLE 3: Factors predicting mothers' behaviors in preventing diarrhea in children (full model), Method: Backward stepwise method

\begin{tabular}{l|l|l|l|l|l|}
\hline Factors & $\mathrm{B}$ & S.E & Wald & Sig. & Exp (B) \\
\hline Age & 0.338 & 0.364 & 0.861 & 0.354 & 1.402 \\
\hline Education & 0.341 & 0.329 & 1.074 & 0.300 & 1.406 \\
\hline Income & 0.674 & 0.325 & 4.302 & 0.038 & 1.963 \\
\hline Knowledge & 0.055 & 0.346 & 0.025 & 0.874 & 1.056 \\
\hline Perceived susceptibility & 0.947 & 0.419 & 5.113 & 0.024 & 2.577 \\
\hline Perceived severity & -1.224 & 0.339 & 13.041 & 0.000 & 0.294 \\
\hline Perceived benefits & 0.425 & 0.431 & 0.970 & 0.325 & 1.530 \\
\hline Perceived barriers & -2.064 & 0.786 & 6.894 & 0.009 & 0.127 \\
\hline Perceived self-efficacy & 2.156 & 0.665 & 10.505 & 0.001 & 8.635 \\
\hline Social support & 0.348 & 0.864 & 0.162 & 0.687 & 1.416 \\
(Constant) & 1.591 & 0.807 & 3.891 & 0.049 & 4.910 \\
\hline Nagelkerke $\mathrm{R}^{2}=0.426$ & & & & &
\end{tabular}

\subsubsection{Forward Stepwise Method}

The best model in predicting mothers' behaviors in preventing diarrhea in children. To identify the best fit model, the result from Backward and Forward stepwise were compared. Apparently results from the Backward stepwise did not yield any model that fit the observed data. However, Forward stepwise method revealed one fitted model (model 4) with Hosmer and Lemeshow statistics of 0.268 which indicated that this model best predicted mothers' behaviors in preventing diarrhea in children with the least number of predictor. The model could predict $39.2 \%$ of the variation of mothers' behaviors. Forward stepwise method which are shown in table 4.

Table 4 shows that the strongest predictor of mothers' behavior was perceived selfefficacy in diarrhea prevention behaviors, $O R=10.701, p<0.01$. The odds of having good prevention behaviors were ten times greater for mothers who had high level perceived self-efficacy in preventing diarrhea. The second predictor was perceived susceptibility to diarrhea, $\mathrm{OR}=3.102, \mathrm{p}<0.01$. The odds of having good prevention behaviors were three times greater for mothers who had high level perceived susceptibility to diarrhea. The third predictor was perceived barriers to diarrhea prevention behaviors, $\mathrm{OR}=0.129$, $p<0.01$. The odds of having good prevention behaviors were 0.1 times greater for mothers who had perceived no barriers to diarrhea prevention behaviors. The fourth predictor was perceived severity of diarrhea, $O R=0.341, p<0.01$. The odds of having good prevention behaviors were reduced by 0.3 times of the mothers who had high level perceived severity of diarrhea compare to those who had low and fair level.

The likelihood of mothers' having good prevention behaviors = 
TABLE 4: Factors predicting mothers' behaviors in preventing diarrhea in children (best model), Method: Forward stepwise method

\begin{tabular}{l|l|l|l|l|l|}
\hline Factors & B & S.E & Wald & Sig. & Exp (B) \\
\hline Perceived susceptibility & 1.132 & 0.387 & 8.545 & 0.003 & 3.102 \\
\hline Perceived severity & -1.078 & 0.310 & 12.009 & 0.001 & 0.341 \\
\hline Perceived barriers & -2.046 & 0.759 & 7.257 & 0.007 & 0.129 \\
\hline Perceived self-efficacy & 2.370 & 0.637 & 13.840 & 0.000 & 10.701 \\
\hline (Constant) & 2.447 & 0.752 & 10.593 & 0.001 & 11.556 \\
\hline Nagelkerke $\mathrm{R}^{2}=0.392$ & & & & &
\end{tabular}

Exp. $2.447+1.132$ (perceived susceptibility) - 1.078 (perceived severity) - 2.046 (perceived barriers) +2.370 (perceived self-efficacy) .

\section{Discussion}

The result shows that over than two thirds (68.3\%) of mothers had good behaviors in preventing diarrhea in children and $46.7 \%$ of the children experienced diarrhea. It has been found that $61 \%$ of mothers had good knowledge about diarrhea in children and $35 \%$ of mothers perceived that their children high susceptible to diarrhea if they did not perform diarrhea prevention behaviors. About $50.7 \%$ of mothers had high perceived severity of diarrhea complication and $34.4 \%$ of mothers had high perceived benefits of diarrhea prevention behaviors.

Based on the current data, the researcher assumes that a few of mothers had obstructions to hone loose bowels prevention behaviors included need of water supply, inaccessibility of latrine and the circumstance in their living range that made them incapable to practice great behaviors in anticipating diarrhea. Some of the mothers lived in stilt house near the river and the sea. With these conditions, they were accustomed to defecating into under the house (pit toilet) or open defecations practice. Some of the mothers also stayed near the woods (inland/very rural area), in which the water supply in the village was still inadequate. Some households use well water, although the water was murky. Some households use bottled water refills; thus, they did not provide boiled drinking water.

According to "the F-diagram" improve water quality is defined as to make water safe to drink and safe for cook preparation. This practice can block the pathway of bacteria that causes of diarrhea in children [23]. Diarrhea are spread by pathogens found in human excreta. The fecal - mouth circle, in which a few of the fecal of a contaminated person are transmitted to the mouth of other individuals. Where sanitation facilities are severely 
arranged and built, ineffectively maintained, utilized wrongly or not utilized at all, their development can set up encourage potential infection transmission, additionally lead to defilement of the environment [24].

In general, any measures to control diarrhea should consider the followings: improved sanitation, improved water quality, increased water supply source, as well as encouraging proper hand washing. Improved sanitation includes proper and safe disposal of feces; defecate in latrine and/or wrapping disposable diapers in plastic bags prior to disposal. While improved water quality measure must ensure that the clean water for household use has passed the process of filtration, disinfection, boiling, putting in a clean container and covered up. Increased water supply source refers to sufficient availability and accessibility to clean water. Proper hand-washing means washing hands with soap and clean water or under running tab water after defecation, after cleaning a child's bottom, before feeding a child and preparing food [23][25]26]. The prevention of diarrhea requires a comprehensive approach to block the pathway preventing transmission of causal agents like feces, bacteria, virus and pathogen.

Another finding explained that perceived risk of contracting an illness and the perceived severity of its consequences is likely to trigger healthy behaviors. However, in the normal situation (without an outbreak) the perceived risk of diarrhea did not motivate people to practice water treatment or other hygiene behavior [27]. On the other hand, a study found that a significant relationship between mother's knowledge and mothers' behavior in taking care their children with diarrhea [28]. Also, a study proofed that water, sanitation, and hygiene (WASH) knowledge is emphatically related with diminished childhood diarrhea; whereas care-seeking behavior for childhood loose bowels is emphatically related with family wealth and maternal education [29].

Concurring to this study, perceived susceptibility to diarrhea decides loose bowels anticipation behaviors. This can be reliable with another study found that perceived susceptibility to diarrhea is impacted to lose bowels anticipation behaviors [18]; moreover, this finding was upheld by health belief model, which portrayed that those who were exceedingly perceived susceptibility to infection would be more likely to require any activity to maintain a strategic distance from the infection [13]. This can be explained that mothers' belief becomes a trigger for their action to prevent diarrhea. In this study, mothers' perceived susceptibility to diarrhea was the second predictor of mothers' behaviors in preventing diarrhea in children aged $1-5$ years. Perform good behaviors in preventing diarrhea in children were three times greater for mothers who had high level perceived susceptible to diarrhea. They were more likely to provide safe water 
drinking, proper dispose of the feces, perform personal and domestic hygiene and provide safety food preparation.

Based to the recent study, perceived severity had an inverse relationship with diarrhea prevention behaviors. Perceived severity alludes to person feelings that concerning the earnestness of the infection. In the event that individuals are prepared, they would take any activities to decrease the seriousness of the illness. In any case, taking certain activities must consider negative perspectives or circumstance. This is often supported by past considers, which found that those who had perceived serious of diarrhea would be more impossible to do great behaviors in avoiding the runs [15]. When the preparation to act was high and the negative aspects were generally weak, the positive action would be taken, or bad habit (vice versa) [13]. This can be explained that there could be other factors, which more influence than mothers' perceived severity of diarrhea; such as the limitation of area, income which is found that it was associated with mothers' behavior in this study. This could lead to have less facility in the household eventually. It can be seen that mothers were highly threat perception, but it could not motivate positive actions because they had some barriers, including in shortage of water supply, in availability of toilet and residential location around the riverside or seaside. This indicated that even they know it is dangerous or they know about the effects of noncompliance the right thing (diarrhea prevention behaviors), but they decide not to comply. This can be caused by the limitation of facilities or infrastructure of village [23][25][26].

It was also presented that mothers' perceived severity of diarrhea was the fourth predictor of mothers' behaviors in preventing diarrhea in children aged 1 - 5 years. Perform good behaviors in preventing diarrhea in children were reduced by 0.3 times of the mothers who had high level perceived severity of diarrhea. This indicates that those who had high level perceived severity of diarrhea were less likely to

provide safe water drinking, proper dispose of the feces, perform personal and domestic hygiene and provide safety food preparation. This could be explained that income probably be more important factor affected to diarrhea prevention behavior. As can be seen within the study that those who were sufficient with family's income, they were more likely to perform good behaviors in preventing diarrhea in children.

Concurring to this current study, perceived benefits of diarrhea prevention behaviors decide mothers' behaviors in avoiding loose bowels in children. Usually steady with the other discoveries, which clarified that those who seen the runs avoidance behaviors have benefits to their children [18]. This finding was supported by health belief model, which depicted that those who seen the activities were useful to decrease the threat of infection; the people would like to require the activities to maintain a strategic distance 
from the illness [13]. This can be supported mothers' perceived benefits of diarrhea prevention could influence mothers' behavior as the result.

According to this study, mothers' perceived barriers to diarrhea avoidance had a reverse relationship with mothers' behaviors in avoiding diarrhea in children. Typically supported by past study, which clarified that those who had seen obstructions to diarrhea anticipation behaviors were more impossible to perform diarrhea avoidance behaviors [15]. Concurring to health belief model, obstructions (the negative perspectives) might disturb the line to taking great activities [13]. The results show that a few of the mothers had a few obstructions to practice great behaviors in avoiding loose bowels including in deficiency of water supply, inaccessibility of can and private circumstance in their living zone.

Some of mothers living in stilt house near the river and the sea. With these conditions, they were accustomed to do defecating into under the house (pit toilets) or open defecations practice. Some mothers also stayed near the woods (inland/very rural area), in which the water supply in the village was still inadequate. Some households use dwell water, although the water was murky. Some households used bottled water refills; thus, they did not provide boiled drinking water. These barriers could make them less likely to perform diarrhea prevention behaviors as the result. Moreover, mothers' perceived barrier to diarrhea prevention behaviors was the third predictor of mothers' behaviors in preventing diarrhea in children aged $1-5$ years. Perform good behaviors in preventing diarrhea in children were 0.1 times greater for mothers who had perceived no barriers to diarrhea prevention behaviors. It can be explained that mothers who had perceived no barriers to diarrhea prevention behaviors, they were more likely to provide safe water drinking, proper dispose of the feces, perform personal and domestic hygiene and provide safety food preparation.

Concurring to this study, mothers' perceived self-efficacy in diarrhea prevention behaviors was determines mothers' behaviors in anticipating diarrhea in children. It has been clarified that those who accepted in their capacity to succeed in performing an activity seem perform healthy behaviors. In other words, they had certainty to actualize the activity for decreasing the danger of the illness. Typically reliable with the past study, which found that mothers who had exceedingly perceived self-efficacy in diarrhea anticipation behaviors would be more likely to do great behaviors in anticipating diarrhea [15]. This is can be implied that perceived self-efficacy influences how people feel and think, then motivating themselves to do any actions; from the start, how much effort will be needed and how long it will be sustained [14]. This can be supported those mothers 
perceived self-efficacy in diarrhea prevention could influence mothers' behaviors in preventing diarrhea as the result.

The result also shows that mothers' perceived self-efficacy in diarrhea prevention behaviors was the strongest predictor of mothers' behaviors in preventing diarrhea in children aged 1 - 5 years. Perform good behaviors in preventing diarrhea in children were ten times greater for mothers who had high level perceived self-efficacy in diarrhea prevention behaviors. They were more likely to provide safe water drinking, proper dispose of the feces, performing personal and domestic hygiene and provide safety food preparation.

WHO stated that the determinants of wellbeing incorporate with social and financial environment, physical environment, and the person's characteristics or behavior. Gotten support from families, companions and communities is connected to superior wellbeing. On the other hand, culture, conventions and the convictions of the family/community are also influence wellbeing [31]. HBM is one hypothesis utilized to assist distinguish the variables that impact person wellbeing behavior. The HBM can also be deciphered as a hypothesis utilized to clarify changes and maintenance of health-related behavior and as a frame of person health-related behavior [33]. Diarrhea is depicted as three or more free or watery stools a day. Disease commonly causes intense diarrhea. Noninfectious etiologies are more common as the term of diarrhea gets to be persistent. Treatment and administration are based on the term and particular etiology. Rehydration treatment is a vital viewpoint of the management of any persistent with diarrhea. Avoidance of irresistible diarrhea incorporates legitimate handwashing to anticipate the spread of contamination [35][38]. The esteem of parental association to lower morbidity and mortality among children [29].

\section{Conclusion}

There were four factors significantly predicted mothers' behaviors in preventing diarrhea in children aged 1 - 5 years. This includes perceived self-efficacy in diarrhea prevention behaviors, perceived susceptibility to diarrhea, perceived barriers to diarrhea prevention behaviors and perceived severity of diarrhea.

\section{Funding}

This work was supported by STIK Indonesia Jaya Palu. 


\section{Acknowledgement}

The authors would like to thank the colleague for their commitment and bolster to this investigate study. The authors are moreover grateful to all the commentators who has their important inputs to the composition and helped in completing this paper.

\section{Conflict of Interest}

The authors have no conflict of interest to declare.

\section{References}

[1] World Health Organization, UNICEF. 1 in 3 people globally do not have access to safe drinking water. Geneva: World Health Organization; 2019.

[2] World Health Organization. Health topic: Diarrhoea. Geneva: WHO; 2021.

[3] World Health Organization. Diarrhoeal disease. Geneva: WHO; 2017.

[4] Profil Kesehatan Indonesia. Laporan tahun 2020. Jakarta: Ministry of Health of Indonesia; 2021. Available from: https://www.kemkes.go.id/downloads/resources/download/pusdatin/profilkesehatan-indonesia/Profil-Kesehatan-Indonesia-Tahun-2020.pdf

[5] Shah SS. Pediatric practice infectious disease. The McGraw-Hill Companies, Inc; 2009.

[6] Digestive disorders health disease. Medscape; 2015. Available from: http://www.webmd.com/digestive-disorders/digestive-diseases-diarrhea

[7] Friedman MR, Bowden VR, Jones E. Family nursing research theory and practice. $5^{\text {th }}$ ed. Upper Saddle River: Pearson Education, Inc.; 2003.

[8] Hamid AYS, Sutarna A, Subekti NB, Yulianti D, Herdina N. Family Nursing: research, theory and practice. $5^{\text {th }}$ ed. Friedman MM, Bowden VR, Jones EG, editors. Jakarta: EGC; 2010. Buku ajar keperawatan keluarga: Riset, teori dan praktek.

[9] Nies MA, McEwen M. Community/public health nursing: promoting the health of populations. $6^{\text {th }}$ ed. Saunders, Elsevier Inc; 2015.

[10] Susanti E, Hariyanto T. Relationship mother's knowledge on food hygiene with diarrhea in infants in the working area Posyandu Jasmine Tlogomas poor villages. Nursing News: Scientific Journal of Nursing. 2017;2(1):174-180.

[11] Hockenberry MJ, Wilson D. Wong's nursing care of infants and children. $10^{\text {th }}$ ed. Canada: Elseiver Mosby; 2016. 
[12] National Institutes of Health. Theories of health behavior, theory at a glance: A guide for health promotion practice. Available from: http://www.orau.gov/cdcynergy/ soc2web/content/activeinformation/resources/theory_at_glance.pdf

[13] Becker MH. The health belief model and personal health behavior. San Francisco: Society for Public Health Education; 1974.

[14] Pender NJ, Murdaugh CL, Parsons MA. Health promotion in nursing practice. $6^{\text {th }}$ ed. Upper Saddle River: Pearson Education, Inc.; 2011.

[15] Morgan MS. Diarrhea preventive behavior among the caregivers of children underfive years old in the Tonle Sap Great Lake floodplains, Siem Reap, Cambodia [M.Sc. Thesis]. Mahidol University; 2014.

[16] Chowdhury F. Diarrhea preventive practice among caregivers of 1 to 5 years children at urban slum area in Chittagong, Bangladesh [M.Sc. Thesis]. Mahidol University; 2010.

[17] Htay WYA, Keiwkarnka B, Hongkailert N. Diarrhea preventive behavior of Myanmar immigrant caregivers with children under-five years in Muang District, Samut Sakhon province, Thailand. 2010. Available from: http://www.aihd.mahidol.ac.th/sites/default/ files/images/new/pdf/journal/janapr2011/1.pdf

[18] Kundu TR, Prateepchaikul L, Ngam KS. Relationship between maternal perceptions and preventive behaviors regarding acute diarrhea of children in Bangladesh. 2010. Available from: http://tar.thailis.or.th/bitstream/123456789/929/1/009.pdf

[19] Badan Pusat Statistik. Kabupaten buol dalam angka. Badan pusat statistik kabupaten buol. 2013.

[20] Dinas Kesehatan Sulawesi Tengah (DinKes Sul-Teng). Profil kesehatan provinsi, Kota Palu, Indonesia. 2012. Available from: http://www.depkes.go.id/resources/download/ profil/PROFIL_KES_PROVINSI_2012/25_Profil_Kes.Prov.SulawesiTengah_2012

[21] McKinney ES, Murray SS, Ashwill J, James SR, Nelson K. Maternal-child nursing. $4^{\text {th }}$ red. Saunders, Elsevier Inc.; 2013.

[22] Polit DF, Beck CT. Nursing research: Generating and assessing evidence for nursing practice. $9^{\text {th }}$ ed. Philadelphia: Lippincott Williams \& Wilkins; 2012.

[23] Environmental health project - EHP. The hygiene improvement framework: A comprehensive approach for preventing childhood diarrhea. Washington, DC: Infectious Diseases and Nutrition Bureau for Global Health; 2004. Available from: http://www.ehproject.org/PDF/Joint_Publications/JP008-HIF.pdf

[24] World Health Organization. Sanitation and health, where to from here? WASH - WHO; 2019. Available from: 
https://cdn.who.int/media/docs/default-source/wash-documents/sanitation-whereto-from-here-20190606.pdf?sfvrsn=de359b_6\&download=true

[25] Centers for Disease Control and Prevention. Handwashing: Clean hands safe lives. CDC; 2015. Available from: http://www.cdc.gov/handwashing/when-howhandwashing.html

[26] Centers for Disease Control and Prevention. The save water and system. CDC; 2014. Available from: http://www.cdc.gov/safewater/disease.html

[27] Figueroa ME, Kincaid LD. Social, cultural and behavioral correlates of household water treatment and storage. The Johns Hopkins Bloomberg School of Public Health Center for Communication Programs; 2010. Available from: http://ccp.jhu.edu/wpcontent/uploads/Household-Water-Treatment-and-Storage-2010.pdf

[28] Arianusyanti R, Utami TA. The relationship of knowledge on the behavior of mothers caring for children toddler with diarrhea. Nursing Journal of Respati Yogyakarta. 2020;7(1):36-41.

[29] Bennion N, et al. Association between WASH-related behaviors and knowledge with childhood diarrhea in Tanzania. International Journal of Environmental Research and Public Health,. 2021;18:4681. https://doi.org/10.3390/ijerph18094681

[30] Hasan MZ, Mehdi GG, de Broucker G, et al. The economic burden of diarrhea in children under 5 years in Bangladesh. International Journal of Infectious Diseases. 2021;107:37-46. doi: 10.1016/j.jijid.2021.04.038

[31] World Health Organization. The determinant of health. Geneva: WHO; 2016. Available from: http://www.who.int/hia/evidence/doh/en/

[32] Oliveira RKL, et al. Influence of socio-economic conditions and maternal knowledge in self-effectiveness for prevention of childhood. Journal Maternal Knowledge for Prevention of Childhood Diarrhea, Esc Anna Nery. 2017;21(4):20160361. DOI: 10.1590/2177-9465-EAN-2016-0361

[33] Tias LH, Pristianty L, Hidayati IR. Behavioral factor analysis of accuracy in using diarrhea medicines at Arjuno Health Center, Malang City with the Health Belief Model (HBM) approach. Farmasains: Jurnal Farmasi Dan Ilmu Kesehatan. 2021;5(2):85-90. https://doi.org/10.22219/farmasains.v5i2.14094

[34] Nemeth V, Pfleghaar N. Diarrhea. Treasure Island (FL): StatPearls Publishing; 2021. Available from: https://www.ncbi.nlm.nih.gov/books/NBK448082/

[35] Pathak P, Munsawaengsub C, Nanthamongkolchai S. Predictive factors of diarrhea preventive practices by caretakers. Journal of Nepal Health Research Council. 2019;17(43);247 - 252. https://doi.org/10.33314/jnhrc.v0i0.1876 
[36] Rumbo H, Wichaikull S, Sanguanprasit B. Factors influencing preventive behaviors of mothers for diarrhea in children aged 15 years in Buol District, Indonesia. Journal of Sociology Study. 2016;6(12):745-753.

[37] Alshammari, B. A., Moussa, S., \& Zaid, A. W.. Knowledge and behavioral practice of mothers about diarrhea in hail region, Saudi Arabia. World Journal of Pharmaceutical Research. 2018;7(3):1661-1674. DOI: 10.20959/wjpr20184-11031

[38] Vecchio AL, Conelli ML, Guarino A. Infections and chronic diarrhea in children. The Pediatric Infectious Disease Journal. 2021;40(7):255-258. DOI: 10.1097/INF.0000000000003182

[39] Mashoto KO, Malebo HM, Msisiri E, Peter E. Prevalence, one week incidence and knowledge on causes of diarrhea: Household survey of under-fives and adults in Mkuranga District, Tanzania. BMC Public Health. 2014;14:985. 